\title{
Synthesis of Iron Nanoparticles by Thermal Decomposition of Diironnonacarbonyl in Ionic Liquid and Their Potential Use as Nanotracers for Mixer Studies in Liquids Feeds
}

\author{
Irina Irgibaeva1, Nikolay Barashkov²* (1), Tamara Sakhno3 ${ }^{3}$ Artur Mantel1, \\ Svetlana Mendigaliyeva1, Irina Barashkova4, Yuriy Sakhno ${ }^{5}$ \\ ${ }^{1}$ Eurasian National University, Nur-Sultan, Kazakhstan \\ ${ }^{2}$ Micro-Tracers, Inc., San Francisco, CA, USA \\ ${ }^{3}$ Poltava University of Economics and Trade, Poltava, Ukraine \\ ${ }^{4}$ Institute of Chemical Physics, Russian Academy of Sciences, Moscow, Russia \\ ${ }^{5}$ University of Delaware, Newark, DE, USA \\ Email: ^Nikolay@microtracers.com
}

How to cite this paper: Irgibaeva, I., Barashkov, N., Sakhno, T., Mantel, A., Mendigaliyeva, S., Barashkova, I. and Sakhno, Y. (2020) Synthesis of Iron Nanoparticles by Thermal Decomposition of Diironnonacarbonyl in Ionic Liquid and Their Potential Use as Nanotracers for Mixer Studies in Liquids Feeds. Advances in Chemical Engineering and Science, 10, 201-209.

https://doi.org/10.4236/aces.2020.103015

Received: June 4, 2020

Accepted: July 11, 2020

Published: July 14, 2020

Copyright ( 2020 by author(s) and Scientific Research Publishing Inc. This work is licensed under the Creative Commons Attribution International License (CC BY 4.0).

http://creativecommons.org/licenses/by/4.0/ (c) (i) Open Access

\begin{abstract}
Iron nanoparticles with dynamic light scattering median diameter around $10 \mathrm{~nm}$ have been prepared by thermal decomposition under a nitrogen atmosphere from diironnonacarbonyl (DINC) dissolved in n-butyl-3-methylimidazolium tetrafluoroborate (BMIMBF). The effect of temperature changes in the range of $170^{\circ} \mathrm{C}-200^{\circ} \mathrm{C}$ and changes in concentration of DINC in BMIMBF in the range of $0.1 \%-0.9 \%$ on the properties of obtained iron nanoparticles has been investigated. The stable dispersion of iron nanoparticle in ethanol has been prepared after separation of nanoparticles from ionic liquid by centrifugation following by their re-dispersion in ethanol. The possibility of quantitative analysis of iron content in ethanol dispersion by deposition of ferromagnetic nanoparticles on the surface of plastic-protected neodymium magnet, dissolution of iron in hydrochloric acid and addition of ammonium thiocyanate solution following by spectrophotometric determination of iron cations at wavelength of $490 \mathrm{~nm}$ has been investigated. The feasibility of using the same approach in case of addition of ethanol dispersion of iron nanoparticles to the liquid animal feeds for evaluation of efficiency of their mixing has been discussed.
\end{abstract}

\section{Keywords}

Ionic Liquids, Magnetic Nanoparticles, Surfactant, Mixing Performance, 
Animal Feed

\section{Introduction}

In recent years, the ionic liquids (ILs) have been extensively evaluated as environmental-friendly or "green" alternatives to conventional organic solvents for synthesis of nanoparticles [1]. Generally speaking, ILs refer to a specific class of molten salts which are liquids at temperatures of $100^{\circ} \mathrm{C}$ or below [2] [3] [4]. ILs have very low vapor pressure and generate virtually no hazardous vapors. Moreover, ILs are composed of charged species, which provide a highly polar medium useful in various applications, such as extraction, separation, catalysis and chemical synthesis medium [5] [6]. The large number of ILs, containing 1-alkyl-3-methyl-imidazolium cation, where alkyl group is butyl, hexyl or nonyl, and anions, such as chloride, bromide, tetrafluoroborate and hexafluorophosphate, have been used for dissolving cellulose [7].

Previously iron nanoparticles have been prepared by thermal decomposition under a nitrogen atmosphere from diironnonacarbonyl (DINC) dissolved in n-butyl-3-methylimidazolium tetrafluoroborate (BMIMBF) [8]. DINC has an almost nonexistent vapor pressure at room temperature. Nonetheless, $\mathrm{Fe}_{2}(\mathrm{CO})_{9}$ has been successfully used to dope carbon nanotubes with iron and to construct iron nanowires used for magneto-resistance and spintronic devices [9] [10]. As reported in these sources, the average atomic percentages of iron in these deposits range from about $50 \%-80 \%$ with Pfeiffer et al. showing a purity as high as 95\% [11] [12].

In this study the iron nanoparticles with dynamic light scattering median diameter around $10-11 \mathrm{~nm}$ were synthesized under similar conditions (Figure 1). The authors followed several narratives in this investigation: 1) influence of the temperature conditions on the size and properties of formed nanoparticles; 2) influence of concentration of DINC in BMIMBF on those parameters; 3) possibility to create a stable dispersion of iron nanoparticles in the liquid animal feeds; 4) feasibility of quantitative analysis of iron nanoparticles magnetically retrieved from the liquid feeds and its applicability for evaluation of the quality of mixing.

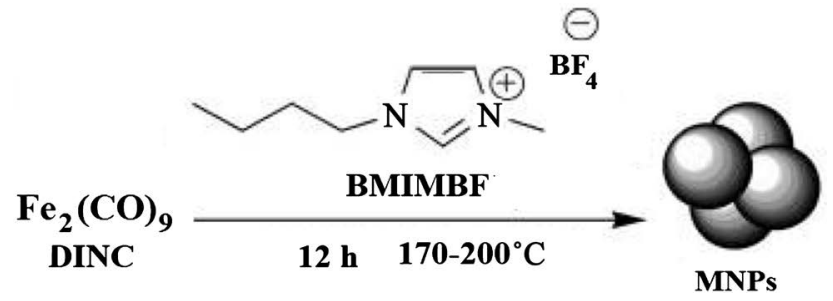

Figure 1. Thermal decomposition diironnonacarbonyl (DINC) dissolved in n-butyl-3methylimidazolium tetrafluoroborate (BMIMBF) with formation of magnetic nanoparticles (MNPs). 


\section{Experimental Part}

\subsection{Synthesis and Redispersion of Nanoparticles}

Diironnonacarbonyl, $\mathrm{Fe}_{2}(\mathrm{CO})_{9}$, DINC, (Cat \# 225460, 98\% purity) and BMIMBF (Cat \# IL-0012-HP, $\mathrm{H}_{2} \mathrm{O}$ content, 100 ppm; Cl- content, 50 ppm) were purchased from Sigma-Aldrich and IoLiTec, respectively. All manipulations were done using Schlenk techniques under dry nitrogen.

The BMIMBF was dried under high vacuum $\left(10^{-3} \mathrm{mbar}\right)$ for several days. Thermal decomposition was carried out under nitrogen or air in a vessel which was connected to an oil bubbler by method described in publication [8]. In a typical experiment the certain amount of $\mathrm{Fe}_{2}(\mathrm{CO})_{9}$ (from 6 to $54 \mathrm{mg}$ ) was dissolved at room temperature in $6.0 \mathrm{~g}$ of the ionic liquid to give a $0.1 \%-0.9 \%$ solution. The solution was slowly heated to $170^{\circ} \mathrm{C}-200^{\circ} \mathrm{C}$ for over a period of $12 \mathrm{~h}$ under stirring. After the mixture was cooled to room temperature under nitrogen, an aliquot of the ionic liquid was collected for microscopic and dynamic light scattering measurements.

Iron nanoparticles were separated by centrifugation (15 min at $2500 \mathrm{rpm}$ under nitrogen) from the BMIMBF, and the ionic liquid can be reused. Two different procedures were used for adding nanoparticles to liquid feeds. According to the first procedure, the collected nanoparticles were redispersed in ethanol at room temperature (about $50 \mathrm{mg}$ of $\mathrm{Fe}$ nanoparticles per $10 \mathrm{ml}$ of ethanol) and added to $200 \mathrm{~g}$ of molasses-based liquid feeds, following by evaporation of ethanol in vacuum at temperature $40^{\circ} \mathrm{C}-50^{\circ} \mathrm{C}$. According to the second procedure, the nanoparticles were redispersed in oleic acid at temperature $35^{\circ} \mathrm{C}$ (about 40 $\mathrm{mg}$ of Fe nanoparticles per $10 \mathrm{ml}(9.0 \mathrm{~g})$ of oleic acid (Sigma-Aldrich, Cat. \#364525, 90\% purity). Prepared dispersion was added to $200 \mathrm{~g}$ of molasses-based liquid feeds containing $\sim 4.9 \mathrm{~g} 28 \%$ aqueous solution of ammonium hydroxide which was sufficient for complete conversion of oleic acid in ammonium oleate.

\subsection{Characterization of Nanoparticles}

UV-VIS absorbance spectra were measured on Cary 60 Agilent spectrophotometer. Transmission electron microscopy (TEM) photographs were taken using a Zeiss LEO 912 transmission electron microscope. Dynamic light scattering measurements were performed using Zetasizer Nano-ZS from Malvern Panalytical.

Four-step procedure has been used in the spectrophotometric method for evaluating stability of iron nanoparticles' dispersion in molasses-based liquid feed:

1) Retrieving iron nanoparticles from prepared suspension with a plastic coated Neodimium magnet;

2) Dissolving nanoparticles in $20 \%$ aqueous solution of $\mathrm{HCl}$;

3) Adjusting $\mathrm{pH}$ of prepared solution to 5.0 (by adding $28 \%$ solution of $\mathrm{NH}_{4} \mathrm{OH}$ ) and mixing it with $1 \%$ aqueous ammonium thiocyanate solution;

4) Dilution of prepared solution with a mixture of $0.1 \mathrm{M}$ aqueous $\mathrm{HCl}$ and ac- 
etone $(1: 1, \mathrm{v} / \mathrm{v})$ and determination of optical density of formed iron thiocyanate solution at $490 \mathrm{~nm}$.

\section{Results and Discussion}

According to data presented in paper [8], the nanoparticles of iron can be prepared from $\mathrm{Fe}_{2}(\mathrm{CO})_{9}$ only in case of thermal decomposition under atmosphere of dry inert gas (argon or nitrogen). Performance of this reaction under air leads to almost complete oxidation of formed nanoparticles of $\mathrm{Fe}$ into $\mathrm{Fe}_{2} \mathrm{O}_{3}$.

Table 1 shows the size of nanoparticles $\left(\mathrm{Fe}\right.$ or $\mathrm{Fe}_{2} \mathrm{O}_{3}$ in case of thermal decomposition under nitrogen or under air, respectively) for two concentrations of $\mathrm{Fe}_{2}(\mathrm{CO})_{9}$ in ionic liquid. It should be noted that data presented in Table 1 show that the size of iron nanoparticles prepared in this study is slightly larger than the size of same nanoparticle synthesized by decomposition $\mathrm{Fe}_{2}(\mathrm{CO})_{9}$ in BMIMBF reported in paper [8] (10.1 - $10.7 \mathrm{~nm})$. The same conclusion can be made regarding the size of $\mathrm{Fe}_{2} \mathrm{O}_{3}$ nanoparticles: $6.9-7.5 \mathrm{~nm}$ in current study) and $6.2-6.4 \mathrm{~nm}$ reported in paper [8]. Our results showed the absence of significant influence of the starting concentration of $\mathrm{Fe}_{2}(\mathrm{CO})_{9}$ in ionic liquid on the size of formed nanoparticles in case of thermal decomposition in nitrogen atmosphere. In case of thermal decomposition under air atmosphere the size of formed iron oxide nanoparticles is slightly larger at higher starting concentration of $\mathrm{Fe}_{2}(\mathrm{CO})_{9}(7.5 \mathrm{~nm}$ vs $6.9 \mathrm{~nm})$.

Figure 2 shows TEM photograph of Fe nanoparticles prepared from $\mathrm{Fe}_{2}(\mathrm{CO})_{9}$. Black iron nanoparticles are magnetic and are able to agglomerate as a result of their superparamagnetic properties [13]. The brown-grey nanoparticles of $\mathrm{Fe}_{2} \mathrm{O}_{3}$ are not magnetic at room temperature. Dispersion of iron nanoparticles in BMIMBF were reproducibly obtained and are stable for several months under dry nitrogen.

In this study we used the spectrophotometric procedure [14] [15] for determination of iron concentration which includes an addition of $1 \%$ aqueous ammonium thiocyanate solution to solution of Fe nanoparticles in $20 \%$ solution $\mathrm{HCl}$, adjusting its $\mathrm{pH}$ to 5.0 (see Experimental part), following by mixing with

Table 1. Size of nanoparticles analyzed by Dynamic Light Scattering in case of decomposition performed under dry nitrogen and under air.

\begin{tabular}{cccc}
\hline $\begin{array}{c}\text { Concentration of } \mathrm{Fe}_{2}(\mathrm{CO})_{9} \\
\text { in BMIMBF, \% }\end{array}$ & $\begin{array}{c}\text { Conditions of } \\
\text { thermode composition }\end{array}$ & $\begin{array}{c}\text { Product of } \\
\text { reaction }\end{array}$ & $\begin{array}{c}\text { Dynamic Light Scattering } \\
\text { Media. Diameter, nm }\end{array}$ \\
\hline 0.1 & Nitrogen & $\mathrm{Fe}$ & 11.2 \\
0.9 & Nitrogen & $\mathrm{Fe}$ & 11.4 \\
0.1 & Air & $\mathrm{Fe}_{2} \mathrm{O}_{3}$ & 6.9 \\
0.9 & Air & $\mathrm{Fe}_{2} \mathrm{O}_{3}$ & 7.5 \\
\hline
\end{tabular}


$0.1 \mathrm{M}$ aqueous $\mathrm{HCl}$ and acetone $(1: 1, \mathrm{v} / \mathrm{v})$ and reading absorbance of prepared solution at $490 \mathrm{~nm}$. Different ratios between diluted aqueous solutions of $\mathrm{HCl}$ and acetone have been tested, and the 1:1 v/v composition appears to be most acceptable in terms of reproducible measurements of the absorbance spectra.

Figure 3 shows the series of absorbance spectra of various ferric chloride solutions mixed with $0.1 \mathrm{M}$ aqueous hydrochloric acid and acetone after addition of excess amount of $1 \%$ aqueous ammonium thiocyanate solution with a range of iron concentration from $1.20 \mathrm{ppm}$ to $2.0 \mathrm{ppm}$. The value of absorbance at wavelengths of $490 \mathrm{~nm}$ has been used for creation of calibration graph (Figure 4) which has a linear character in the chosen range of iron concentration.

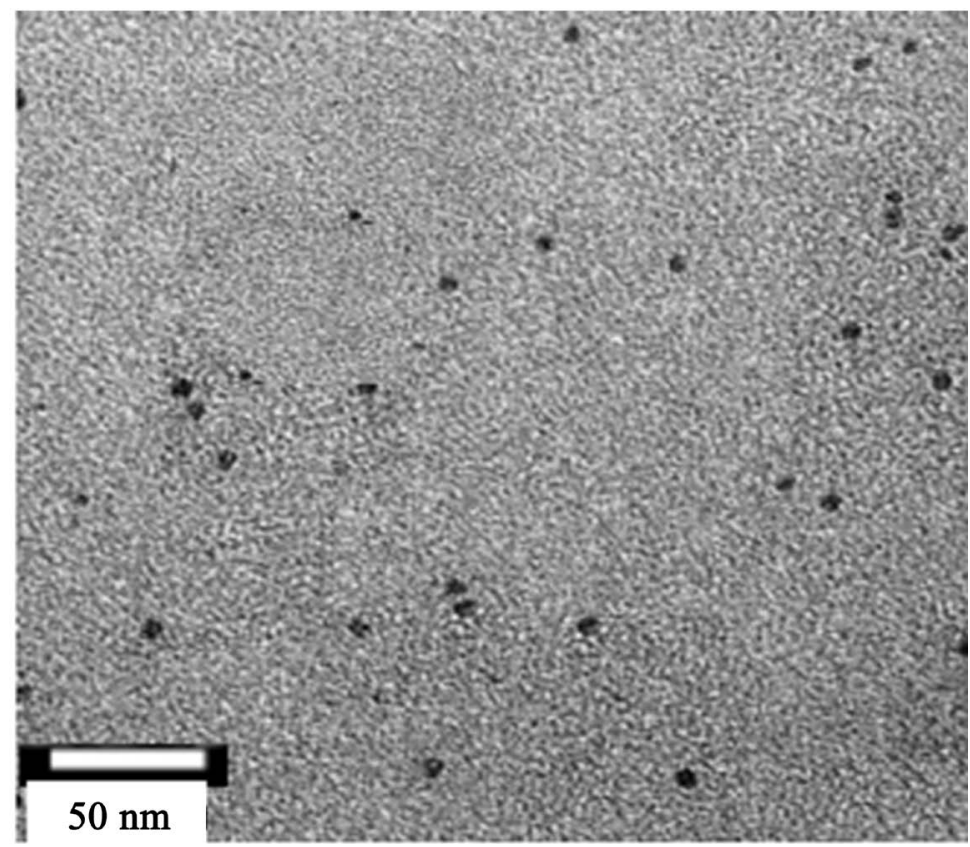

Figure 2. TEM photograph showing Fe nanoparticles from $\mathrm{Fe}_{2}(\mathrm{CO})_{9}$ in BMIMBF prepared by thermal decomposition (entry 2 in Table 1).

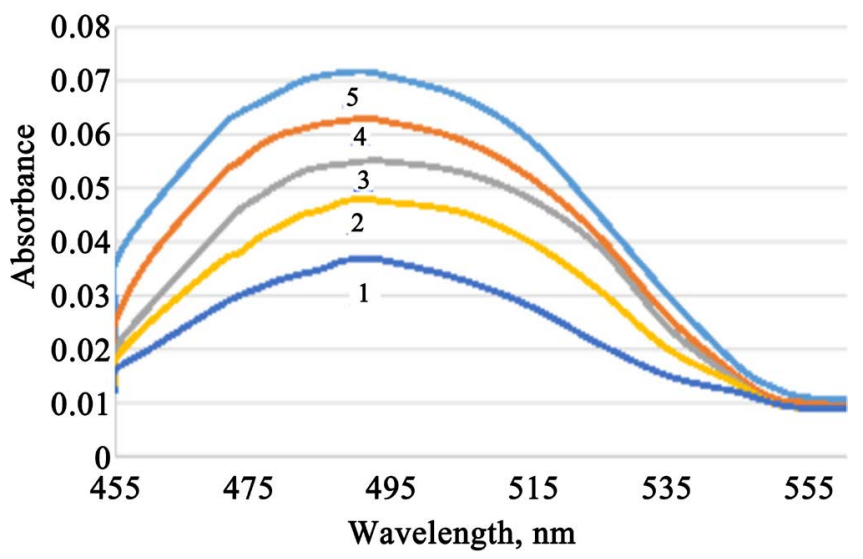

Figure 3. Absorbance spectra of various ferric chloride solutions mixed with $0.1 \mathrm{M}$ aqueous hydrochloric acid and acetone after addition of excess amount of $1 \%$ aqueous ammonium thiocyanate solution. $1-1.20 \mathrm{ppm}, 2-1.45 \mathrm{ppm}, 3-1.57 \mathrm{ppm}, 4-1.71 \mathrm{ppm}$, and $5-2.0 \mathrm{ppm}$. 


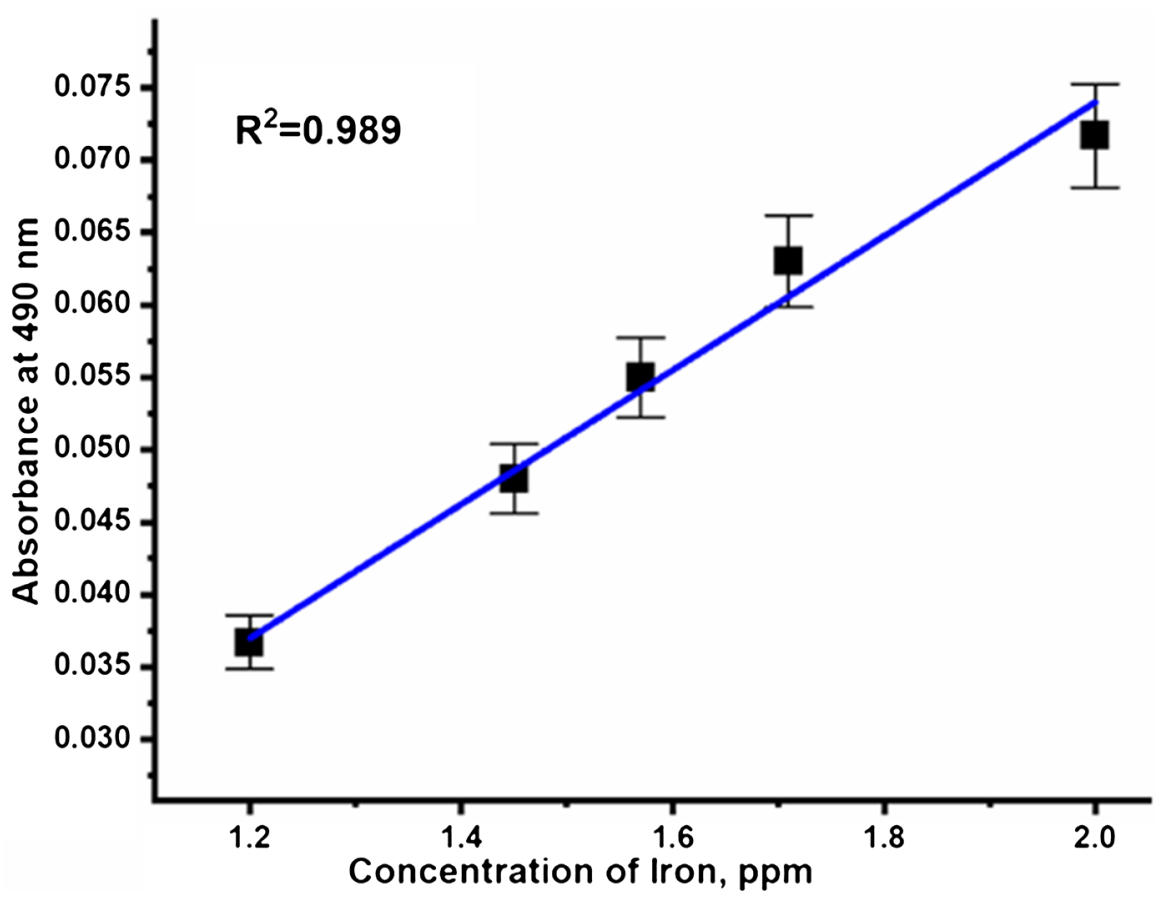

Figure 4. Calibration graph for spectrophotometric determination of iron content in analyzed samples.

\section{Application of Ferromagnetic Iron Nanoparticles}

Potential applications of prepared stable suspension of ferromagnetic iron nanoparticles are related to validating mixing of liquid feeds, as well as to coding liquid additives, such as enzymes, and evaluation of their distribution in premixes and final feeds. Comparison between two different procedures used for adding nanoparticles to liquid feeds (see Experimental Part) shows that redispersing them in ethanol before addition to molasses based feeds, following by evaporation of ethanol in vacuum at elevated temperature leads to relatively unstable suspension. Particularly after one hour of storage at room temperature a majority of added iron nanoparticles forms relatively large aggregates which are not equally suspended in the volume of liquid feed. ln contrary, redispersing nanoparticles in oleic acid following by addition of prepared suspension to molasses based liquid feeds containing a certain amount of ammonium hydroxide leads to formation of stable suspension which doesn't show any sign of precipitation after storage for several days at room temperature.

In our previous studies [16] [17] [18] we demonstrated that ammonium oleate (which is product of interaction oleic acid in ammonium hydroxide in the current study) is very efficient surfactant for forming stable suspension of magnetic iron oxide nanoparticles.

Here we report the use of iron nanoparticles as components of magnetically retrievable liquid marker (tracer) have been tested in laboratory trials. The laboratory trial with an addition of liquid tracer to molasses based liquid feed followed by retrieving the ferromagnetic nanoparticles and analyzing the content of 
Table 2. Results of homogeneity test for laboratory trial with stable suspension of ferromagnetic iron nanoparticles (tracer recover is $\sim 82 \%$ ).

\begin{tabular}{|c|c|c|c|c|c|c|c|c|}
\hline \multirow[b]{2}{*}{ Parameter } & \multicolumn{8}{|c|}{ \# analyzed samples } \\
\hline & 1 & 2 & 3 & 4 & 5 & 6 & 7 & 8 \\
\hline $\begin{array}{l}\text { Concentration of iron in sample } \\
\text { (absorbance units at } 490 \mathrm{~nm}) \times 10^{3}\end{array}$ & 64 & 68 & 55 & 71 & 63 & 65 & 60 & 61 \\
\hline Mean value of concentration & & & & & 63.38 & & & \\
\hline Standard deviation, $\%$ & & & & & 4.93 & & & \\
\hline Coefficient of variation, $\%$ & & & & & 7.78 & & & \\
\hline Chi-square & & & & & 2.68 & & & \\
\hline Probability,\% & & & & & 84.77 & & & \\
\hline
\end{tabular}

iron in them using the calibration graph (Figure 3) showed approximately $82 \%$ tracer recovers.

Table 2 shows the results of one of several laboratory trials where an addition of $40 \mathrm{mg}$ iron nanoparticles has been used for evaluation of mixing quality for several liquid ingredients in $200 \mathrm{~g}$ of molasses based liquid feed mix. The data presented in Table 2 were interpreted using Poisson and Chi squared statistics [19]. Treating a series of counts (absorbance values) as a Poisson distribution, the mix is judged "complete" in case if the counts would occur by chance in more that 5 of 100 studies. If the counts would occur by chance from a "perfect" mix in fewer than 5 of 100 studies, the mix is judged "probably incomplete". If the counts would occur by chance from a "perfect" mix in fewer than one of 100 studies, the mix is judged incomplete.

\section{Conclusions}

1) Method for making iron nanoparticles by thermal decomposition of $\mathrm{Fe}_{2}(\mathrm{CO})_{9}$ has been developed and their stability in several liquid systems has been evaluated.

2) Possibility of using prepared stable suspension of ferromagnetic nanoparticles for validating mixing of liquid feeds has been demonstrated.

3) Further study will include the evaluation of feasibility to use ferromagnetic nanoparticles for validating mixing of liquid feeds containing some amount of solid mineral additives such as zinc complexes of amino acids traditionally added to liquid animal feed.

\section{Conflicts of Interest}

The authors declare no conflicts of interest regarding the publication of this paper.

\section{References}

[1] Gaiser, H.F., Popescu, R., Gerthsen, D. and Feldmann, C. (2020) Ionic-Liquid-Based Synthesis of GaN Nanoparticles. Chemical Communications, 56, 2312-2315. 
https://doi.org/10.1039/C9CC09133E

[2] Sakhno, T.V., Barashkov, N.N., Irgibaeva, I.S., Mendigaliyeva, S. and Bostan, D.S. (2020) Ionic Liquids and Deep Eutectic Solvents and Their Use for Dissolving Animal Hair. Advances in Chemical Engineering and Science, 10, 40-51. https://doi.org/10.4236/aces.2020.101003

[3] Plechkova, N.V. and Seddon, K.R. (2008) Applications of Ionic Liquids in the Chemical Industry. Chemical Society Reviews, 37, 123-150. https://doi.org/10.1039/B006677I

[4] Riabchunova, A.V., Karabtsova, V.M. and Kalugin, O.N. (2018) Density and Solvation Effects of Imidazolium Based Ionic Liquids in Propylene Carbonate. Kharkov University Bulletin. Chemical Series, 31, 21-31.

[5] Abbott, A.P., Capper, G., Davies, D.L. and Rasheed, R.K. (2004) Ionic Liquid Analogues Formed from Hydrated Metal Salts. Chemistry-A European Journal, 10, 3769-3774. https://doi.org/10.1002/chem.200400127

[6] Abbott, A.P., Capper, G., Davies, D.L. and Rasheed, R. (2004) Ionic Liquids Based upon Metal Halide/Substituted Quaternary Ammonium Salt Mixtures. Inorganic Chemistry, 43, 3447-3452. https://doi.org/10.1021/ic049931s

[7] Swatloski, R.P., Spear, S.K., Holbrey, J.D. and Rogers, R.D. (2002) Dissolution of Cellulose [Correction of Cellose] with Ionic Liquids. Journal of the American Chemical Society, 124, 4974-4975. https://doi.org/10.1021/ja025790m

[8] Krämer, J., Redel, E., Thomann, R. and Janiak, Ch. (2008) Use of Ionic Liquids for the Synthesis of Iron, Ruthenium, and Osmium Nanoparticles from Their Metal Carbonyl Precursors. Organometallics, 27, 1976-1978. https://doi.org/10.1021/om800056z

[9] Córdoba, R., Han, D.S. and Koopmans, B. (2016) Manipulating the Switching in Modulated Iron Nanowires Grown by Focused Electron Beam Induced Deposition. Microelectronic Engineering, 153, 60-65. https://doi.org/10.1016/j.mee.2016.01.032

[10] Lavrijsen, R., Córdoba, R., Schoenaker, F.J., Ellis, T.H., Barcones, B., Kohlhepp, J.T., Swagten, H.J.M., Koopmans, B., Teresa, J.M.D., Magén, C., Ibarra, M.R., Trompenaars, P. and Mulders, J.J.L. (2011) Fe:O:C Grown by Focused-Electron-Beam-Induced Deposition: Magnetic and Electric Properties. Nanotechnology, 22, Article ID: 025302. https://doi.org/10.1088/0957-4484/22/2/025302

[11] Pfeiffer, B., Erichsen, T., Epler, E., Volkert, C.A., Trompenaars, P. and Nowak, C. (2015) Characterization of Nanoporous Materials with Atom Probe Tomography. Microscopy and Microanalysis, 21, 557-563. https://doi.org/10.1017/S1431927615000501

[12] Beljaars, M. (2008) Electron Beam Induced Deposition of Iron. Master's Thesis, Eindhoven University of Technology, Eindhoven.

[13] Mastai, Y. and Gedanken, A. (2004) Sonochemistry and Other Novel Methods Developed for the Synthesis of Nanoparticles. In: Rao, C.N.R., Müller, A. and Cheetham, A.K., Eds., Chemistry of Nanomaterials, Wiley-VCH, Weinheim, Vol. 1, 113-169.

[14] Martins, F.G., Andrade, J.F., Pimenta, A.C., Lourenço, L.M., Castro, J.R.M. and Balbo, V.R. (2005) Spectrophotometric Study of Iron Oxidation in the Iron(II)/Thiocyanate/Acetone System and Some Analytical Applications. Eclética Química, 30, 63-71. https://doi.org/10.1590/S0100-46702005000300008

[15] De Berg, K., Maeder, M. and Clifford, S. (2016) A New Approach to the Equilibrium Study of Iron(III) Thiocyanates Which Accounts for the Kinetic Instability of 
the Complexes Particularly Observable under High Thiocyanate Concentrations. Inorganica Chimica Acta, 445, 155-159.

https://doi.org/10.1016/j.ica.2016.02.052

[16] Barashkov, N., Eisenberg, D., Eisenberg, S. and Mohnke, J. (2007) Ferromagnetic Microtracers and Their Use in Feed Applications. XII International Feed Technology Symposium, Novi Sad, 13-16 November 2007, 1-8.

https://studylib.net/doc/7485298/ferromagnetic-microtracers-and-their-use-in-feed -applications

[17] Barashkov, N.N., Eisenberg, D., Novikova, T.S., Irgibaeva, I.S. and Mantel, A. (2010) Stable Suspension of Mixed Iron Oxide/Cobalt Oxide Nanoparticles in Aqueous Surfactant Solutions and Their Use for Mixer Studies in Liquids Feeds. 240 th American Chemical Society National Meeting \& Exposition Innovation from Discovery to Application PHYS, Boston, August 2010, 1-10.

https://tpa.acs.org/abstract/240tNM-310779/stable-suspension-of-mixed-iron-oxideco balt-oxide-nanoparticles-in-aqueous-surfactant-solutions-and-their-use-for-mixer-stu dies-in-liquids-feeds

[18] Barashkov, N., Sakhno, T., Eisenberg, D., Irgibaeva, I., Yergeshbayeva, S. and Novikova, T. (2013) Stable Suspension of Mixed Iron Oxide/Manganese Oxide Nanoparticles in Aqueous Surfactant Solutions and Their Use for Mixer Studies in Liquids Feeds. AIChE Annual Meeting Global Challenges for Engineering a Sustainable Future, San Francisco, 3-8 November 2013, 1-9.

https://aiche.confex.com/aiche/2013/webprogram/Paper305825.html

[19] Sakhno, T.V., Pisarenko, P.V., Korotkova, I.V., Omelian, O.M. and Barashkov, N.N. (2018) The Application of Statistical Methods of Quality Management by GMP+ Standards Using Ferromagnetic Microtracers. Grain Products and Mixed Fodder's, 18, 39-44. https://doi.org/10.15673/gpmf.v18i3.1078 